\title{
PRASASTI TAMBELINGAN III
}

\section{Sukarto Karto Atmodjo}

Keywords: epigraphy; philology; Bali; hindu; inscription

\section{How to Cite:}

Atmodjo, S. K. (1987). PRASASTI TAMBELINGAN III. Berkala Arkeologi, 8(2), 27-35. https://doi.org/10.30883/jba.v8i2.490

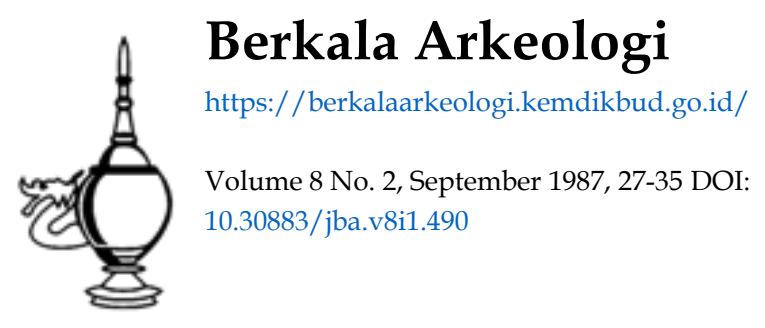




\section{PRASASTI TAMBÊLINGAN III}

M.M. Sukarto K. Atmodjo

I. Sugih tanpa bandha

Digdaya tanpa haji

Ngalurug tanpa bala

Mênang tanpa ngasorakên

II. Trimah mawi pasrah

Suwung pamrih, tebih ajrih

Langgêng tan ana susah, tan ana bungah Antêng maṇthêng, sugêng jênêng.

Drs. RM.P. Sosrokartono. ${ }^{1}$

Prasasti Tambêlingan disimpan di Pura Ratur desa Gobleg (Kabupaten Buleleng) dan merupakan prasasti tembaga. Transkripsi (alih-aksara) pertama dikerjakan oleh P.V. van Stein Callenfels dan dimuat dalam Epigraphia Balica I (VBG, deel LXVI, 1926, hlm. 7-13) tanpa pencatatan ukuran prasasti (afmetingen niet opgeteekend). Oleh Van Stein Callenfels prasasti itu dibedakan menjadi tiga kelompok, yaitu:

1. Oorkonde A.

Prasasti yang masih tersimpan hanya terdiri atas selembar lempengan tembaga, sedangkan lempengan lainnya belum ditemukan. Dicatat oleh R. Goris dalam Prasasti Bali I (PB I) dengan nomer 110 , Gobleg, Pura Batur A. Isinya mengenai anak banwa di tamblingan (penduduk di Tamblingan). Karena prasasti dimulai dengan kalimat yumu pakatahu (ketahuilah kamu sekalian), oleh Goris diperkirakan berasal dari raja Sang Ratu Srī Ugrasena yang memerintah sekitar tahun 844 Saka (922 M) dan 888 Saka (966 M). Prasasti menyebut nama desa Tamblingan dan selanjutnya penulis sebut prasasti Tambêlingan I. Perlu dijelaskan bahwa nama Tamblingan sama dengan Tambêlingan. 


\section{Oorkonde B.}

Prasasti yang masih tersimpan terdiri atas lima lempengan tembaga, yaitu lembar 2, 5, 6, 7 dan bagian penutup. Oleh Goris dicatat dalam PB I dengan nomer 1011, Gobleg Pura Batur B. Tarikh prasasti tidak dapat diketahui secara pasti, karena lembar pertama tidak ada. Hal ini berlainan dengan prasasti Srí Ugrasena yang menyebut angka-tahun pada lembar terakhir. Menurut perkiraan Goris, oorkonde B (prasasti B) ini susunan kalimatnya sesuai dengan prasasti dari tahun 971 Saka (1049 M) dan 976 Saka (1054 M), yaitu prasasti dari zaman raja Anak Wungśu. Isinya mengenai karāman i tambêlingan (penduduk desa di Tambêlingan). Prasasti B selanjutnya penulis sebut Tambêlingan II.

\section{Oorkonde C.}

Prasasti hanya terdiri atas selembar lempengan tembaga dan lengkap. Oleh Goris dicatat dalam PB I dengan nomer 902, Gobleg, Pura Batur C. Berangka-tahun 1320 Saka (1398 M) dan menyebut raja sang mokta ring wişnubhawana (yang dicandikan di Wisnubhawana), yaitu raja Wijarājasa atau Bhre Wèngkêr (di Jawa Timur). Prasasti membicarakan masalah pandewsi ring tambêlingan (pandai besi di Tambêlingan). Selanjutnya tembaga bertulis ini penulis sebut prasasti Tambelingan III.

Prasasti Tambêlingan III ditulis pada kedua belah sisinya, yaitu sisi depan (recto) dan belakang (verso). Setiap sisi dipahat dengan empat baris kalimat, menggunakan huruf dan bahasa Jawa Kuna yang mendekati langgam bahasa Jawa Tengahan (Middle Javanese). Menyebut nama Pãduka Bhatțara Śri Parameśwara Sang Mokta Ring Wișnubhawana, dan bertarikh 1320 Saka (1398 M). Nama Tambêlingan sekarang menjadi nama sebuah danau di pzdalaman pulau Bali, berdekatan letaknya dengan danau Bratan. Seperti telah diterangkan di atas, prasasti Tambêlingan III (juga Tambêlingan I dan II) diterbitkan oleh Van Stein Callenfels dalam Epigraphia Balica I. Isi pokok mengenai perintah raja supaya para pandai besi (apande 
wsi) dari Tambêlingan kembali ke desa Tambêlingan. Selain ketiga prasasti Tambelingan tersebut, penulis pernah pula menemukan prasasti dari raja Jayapangus yang menyebut nama karāman BuyanSanding-Tamblingan. Berita terakhir yang penulis terima dari Bali mengatakan bahwa baru-baru ini di Bali juga ditemukan sebuah prasasti tembaga yang isinya sama dengan Tambelingan III. Apabila benar demikian, maka prasasti baru itu dapat disebut prasasti Tambê. lingan IV.

Untuk memberikan gambaran yang lebih jelas, di bawah ini penulis cantumkan isi prasasti Tambelingan III selengkapnya berdasarkan alih aksara Van Stein Callenfels. Alih aksara selengkapnya sebagai berikut:

la. 1. Iku wruhane kang para mantring ularan samudaya, makanguni hupapatti, hangarêp lawangan, yen andikaningo

2 ng magêhakên indikanira talāmpakanira pāduka bhaț̣ara śri parameswara sang mokta ring wișnubhawana, de-

3. ne kang apandewsi ring tambêlingan, irehane muliha mareng tambêlingan manih, para mantri ta hangantrmakna, a-

4. ryya cêngcêng tãyo sidigawe kang kasujiwana ning tambêlingan, lawan āryya cêngcêng irehane lungaha saking tambêli-

Ib. 1. ngan, hangêreng logajah, lawan dening pangraga skarekang kasujiwana ring tambêlingan, ingong añjênêngakên sa-

2. tak ring salawang nangkèn kawolu, dening paranakan ing deśa, irehane kahidêpa ring tambêlingan, hun ısan, pa-

3. ngi, kdu, têngahmêl, kang rājamudra yen uwus kawaca kagugona dene kang apande wsi ring tambêlingan. tithi,

4. ka, 10 , i saka, $1320 / /-/ /$

Berarti lebih-kurang sebagai berikut:

la. 1. Ketahuilah para menteri Ularan semuanya, lebih-lebih Hupapatti, yang datang menghadap pintu (hangarêp lawang an). ${ }^{2}$ kalau perintah saya 
2 memperkokoh sabda telapak beliau ${ }^{3}$ Paduka Bhattara Sỡ Parameśwara yang dicandikan (sang mokta) di Wiṣnubhawana. ${ }^{4}$

3 bahwa mereka yang bekerja sebagai pandai besi (kang apandewsi) di Tambêlingan. supaya pulang ke Tambêlingan lagi, para menteri akan menghantarkannya (hangantrmakna), 5

4. Äryya Cêngcêng (Āryya Kêncêng dalam babad) janganlah mengganggu (tãyo sidiga've $)^{6}$ kehidupan (kasujiwana) ${ }^{7}$ desa Tambêlingan, dan Aryya Cêngcêng supaya pergi (lungaha) dari Tambêlingan, ${ }^{8}$

ib. 1 dan bertempat-tinggal di Logajah, ${ }^{9}$ sedangkan iuran (pajak) pangragaskar (upacara kebaktian dengan bunga) di Tambe. lingan, saya menetapkannya (ingong añjènêngakên) ${ }^{10}$

2. sebesar 200 (satak) $^{11}$ setiap pintu (salawang) dan setiap bulan Kawolu (kedelapan), dan penduduk desa (paranakan ing deśa $)^{12}$ supaya memperhatikannya, yaitu desa-desa di: Tambélingan. Hunusan,

3. Pangi, Kdu (cf. Kedu di Jawa Tengah), Têngahmell. Selanjut nya rájamudra (prasasti, surat raja) ini kalau sudah dibaca (kawaca) supaya diindahkan (kagugona) oleh para pandai besi (kang apandewsi) di Tambêlingan. tanggal

4. ka, 10 , tahun Saka $1320 / /$ - //

Demikianlah alih-aksara dan juga terjemahan prasasti Tambê. lingan III yang berangka-tahun $1398 \mathrm{M}$, yang mengatakan bahwa desa itu dihuni oleh kelompok pandai besi (pande wsi). Oleh karena sesuatu hal, mungkin masalah pangragaskar, terpaksa para pandai besi tersebut harus pergi meninggalkan desa Tambêlingan. Setelah turun surat perintah Sri Parameswara sang mokta ring Wisnubhawana yang berupa rājamudra, kelompok pandai besi tersebut diperintahkan pulang kembali ke Tambêlingan (muliha mareng tambêlingan manih). Selanjutnya Āryya Cêngcêng, seorang pejabat tinggi yang menyebabkan timbulnya sengketa, diperintahkan agar meninggalkan Tambêlingan dan bertempat-tinggal di Logajah (lawan āryya 
cêngcêng irehane lungaha saking tambêlingan, hangêreng logajah). Selain itu di dalam prasasti yang lebih tua, yaitu tembaga BuyanSanding-Tamblingan dari raja Jayapangus $(1181 \mathrm{M}$ ) dikatakan bahwa sebagian penduduk desa itu, apabila berbuat salah (yan hana rowang nya sakarāman); tetapi kemudian membayar denda pamucuk, mereka diperbolehkan melakukan pekerjaan candala (wnanga yanambutagawening candalakarmma). ${ }^{13}$ Sudah cukup jelas bahwa yang dimaksud desa Tamblingan (dari kelompok Buyan-Sanding-Tamblingan) pada tahun $1181 \mathrm{M}$, sama dengan desa Tambêlingan pada tahun $1398 \mathrm{M}$ atau menjadi nama sebuah danau yang sekarang disebut danau Tamblingan (dekat danau Bratan). Tentunya desa Tambèlingan pada jaman dahulu memang terletak di pinggir danau yang sekarang bernama Tamblingan. Selain itu perlu juga diteliti peranan golongan Pande (clan Pande) yang cukup terkenal di Bali sekarang. Mungkin sekali golongan Pande tersebut sebagian merupakan keturunan pandai besi (apande wsi) yang pernah meninggalkan desa Tambêlingan.

Perlu ditambahkan di sini bahwa di sekitar danau Bratan terdapat beberapa buah palungan batu yang berukuran panjang satu mèter dan dalam bagian lobangnya setengah meter. Van Heekeren dalam bukunya 'Proto-Historic Sarcophagi on Bali' (Berita Dinas Purbakala No. 2, Jakarta 1955, hlm. 9) masih ragu-ragu mengatakan, apakah palungan tersebut merupakan peti-mayat ataukah tidak (The primary problem, however, is whether or not the stone troughs are sarcophagi). Peninjauan penulis ke danau Bratan menunjukkan bahwa di sekitar palungan batu tersebut banyak ditemukan tai-besi atau buangan besi-tuangan. Dengan demikian dapat dipastikan bahwa palungan batu tersebut dahulu berkaitan dengan usaha pekerjaan para pandai besi. Demikian pula palungan batu tersebut tidak mempunyai tonjolan seperti sarkofagus pada umumnya (The Bratan troughs have no protruding knobs and this is an essential characteristics of the Balinese sarcophagi). Dalam Notulen Bataviaasch Genootschap (NBG LVIII, 1920, Bijlage III, hlm6. 183) dikatakan sebagai berikut: "Volgens de overlevering bestond hier in vroeger tijd 
een rijkje van smeden, dat door list door naburige rijkjes tenval werd gebracht. De goud- en zilversmeden in vlak bij Singaradja gelegen, moeten nog uit dat rijkje, aan het Bratanmeer stammen." ("Menurut ceritera, dahulu di sini terdapat kerajaan para pandai, tetapi dengan tipu-muslihat tertentu kemudian dihancurkan oleh kerajaan di sekitarnya. Para pandai mas dan perak di dekat Singaraja, tentulah berasal dari kerajaan di daerah danau Bratan tersebut)." Demikianlah sekali lagi perlu dijelaskan bahwa palungan batu (stone troughs) tersebut bukan sarkofagus, melainkan palungan batu untuk menyimpan air atau mencelup alat (senjata) besi yang panas membara.

Menarik perhatian bahwa pekerjaan sebagai tukang pandai (pandai mas, tembaga, besi), perundagian, dan pekerjaan tukang lainnya, dahulu termasuk pekerjaan candalā (candalākarmma). Dalam kitab lontar Agama Adigama disebut delapan golongan candala (așta candala) yang terdiri atas beberapa orang (kelompok) pengrajin yang jumlahnya sampai delapan belas, yaitu:

1. Undagi (undagi),

2. Amalantên (pencuci pakaian),

3. Angūgā,

4. Anggabag (pencuci, penggosok, pembersih),

5.. Acirigimani,

6. Angulès (pembuat kain, tutup),

7. Ambêrêkis,

8. Amahat (penyadap enau, kelapa, pembuat tuak),

9. Apande wsi (pandai besi),

10. Apande mas (pandai mas),

11. Katambran (pandai tembaga),

12. Apande sisinghen (pembuat senjata tajam ?),

13. Añjyun (pembuat gerabah, jun),

14. Apandyagong (pandai/pembuat gong, gamelan ?)

15. Anglimar (penenun sutra halus?),

16. Ambêdèl (Jawa Baru: medel),

17. Ambalênjing,

18. Añjalagraha (tukang kayu). 
Tetapi menurut kitab \$lokantara yang dimaksud golongan candaia itu terdiri atas lima macam pengrajin atau pekerja (ikang sinangguh candala ring loka. lima kwehnya), yaitu:

1. Suräsut

= amahat (pembuat tuak).

2. Krmidāha

= amalantên (pencuci pakaian),

3. Prānaghna

= anjagal (pembantai binatang),

4. Kumbhakaraka = andyun (pembuat jun, gerabah),

5. Dhātudagdhā = apande mās (pandai mas).

Selanjutnya dalam prasasti Jawa Kuna dan Bali Kuna juga disebut bermacam-macam kelompok pandai (pande) dan undagi (undahagi. undagi), yait $\lrcorner$ :

1. Pande wsi (pandai besi),

2. Pande tambra (pandai tembaga),

3. Pande kangsa (pandai perunggu),

4. Pañde salaka (pandai selaka, perak),

5. Pañde mãs (pandai mas),

6. Pande singya-singyan (pandai pembuat senjata tajam, logam cair),

7. Pande dadap (pembuat tameng, perhiasan?).

8. Pande dang (pembuat alat memasak dandang atau senjata/ alat dandang),

9.. Pande kalang (pembuat alat tukang kayu ?),

10. Undagi lancang (undagi perahu),

11. Undagi batu (tukang batu).

12. Undagi pangarung (ahli pembuat aungan, terowongan),

13. Undagi kayu (tukang kayu),

14. Undagi rumah (ahli pembuat rumah).

Sebagai penutup karangan singkat ini penulis menyimpulkan, bahwa masyarakat pandai (pande), undagi (undagi) dan ketrampilan lainnya, meskipun pada zaman dahulu termasuk pekerjaan candalā (candaläkarmma) dan merupakan golongan rendah (di bawah sudra), tetapi tetap merupakan tulang-punggung kehidupan sosial dan perekonomian rakyat. Oleh karena itu raja memperbolehkan kelompok 
masyarakat tertentu melakukan pekerjaan atau tugas para candalá. Maka di sinilah letak kemampuan, toleransi, gotong-royong, dan local genius nenek-moyang kita, yang tidak semata-mata membedakan antara golongan (kasta) tertinggi dan terendah. Hal yang demikian sangat sulit dan sukar terjadi di negara asalnya India, tempat pertama yang mengembangkan sistem empat kasta atau catur warnna (the Four-castes) dan golongan yang berada di luar kasta (the Outcaste), termasuk kelompok candalā.

Sekian dan terimakasih. In Omnibus Caritas (Dalam segalanya cinta-kasih).

\section{CATATAN:}

1. Kata mutiara dari Raden Mas Panji Sosrokartono itu (kakak Raden Ajeng Kartini) berarti lebih-kurang sebagai berikut:

I. Kaya tanpa harta-benda,

Kebal dan berani tanpa azimat,

Pergi berperang tanpà bala-tentara.

Menang tanpa mengalahkan.

II. Menerima dengan pasrah,

Sepi pamrih, dan jauh dari rasa takut,

Langgeng tidak susah, tidak gembira,

Tenang berkonsentrasi, selamat bahagia nama pribadi.

2. Hangarêp lawangan berarti: di depan pintu (cf. ngarep lawang), yang dimaksud mungkin datang menghadap.

3. Talampakanira berarti: telapak kaki beliau. Untuk penghormatan. Cf. duli paduka (debu sepatu), Cokorda (cokor: kaki, Sampeyan Dalêm (kaki raja).

4. Cf. Raden Sumirat (Bhre Pandan Salas I) yang dicandikan di Jinggan (Wișnupura) dan meninggal tahun 1323 Saka (1401 M).

5. Mungkin dari hantr (hantar, kawal).

6. Perkataan tāyo jelas dari ta-ayo (aywa): janganlah.

Sidigawe mungkin sama sadigawe: mengganggu, berbuat jahat. Apabila sama dengan siddhikäryya berarti: karya yang baik. 
7. Kasujiwana dari sujiwana, mungkin berarti: kehidupan, keselamatan. Cf. sañjiwana: air hidup, amrta

8. Lungaha saking tambêlingan: supaya (harus) pergi dari Tambelingan.

9. Logajah - Lwagajah - Airgajah - Goa Gajah sekarang di sebelah Barat Bedahulu. Karena bentuk huruf 1 mirip g, maka lwa kemudian dibaca gwa dan kebetulan di tempat tersebut terdapat goa purbakala (lwa: air, sungai).

10. Anjenengaken berarti: mendirikan, menetapkan, menentukan.

11. Cf. Tuna satak bathi sanak (rugi 200 untung teman).

12. Paranakan - para anakan - para penduduk.

13. Candalā, Mleccha, Tuccha adalah golongan di luar kasta dan lebih rendah dari kasta sudra. Disebut pula yang tidak boleh disinggung (The Untouchable).

\section{DAFTAR PUSTAKA}

Goris, Roelof. 1954 Prasasti Bali I (Inscripties Voor Anak Wungicu, Band I), diterbitkan oleh Lembaga Bahasa dan Budaya, Universitet Indonesia .

Heekeren, HR. van. 1955. Proto-Histor ic Sarcophagi In Bali, Berita Dinas Purbakala, No. 2, Jakarta.

Sukarto K. Atmodjo, M.M. 1970 Prasasti Buyan-Sanding-Tamblingan dari jaman raja Jayapangus, makalah pada Seminar Sejarah Nasional II. Yogyakarta (setensilan hlm. 1-56).

Sukarto K. Atmodjo, M.M. 1985. Data Perundagian Di Dalam Prasasti Kuno, makalah pada Diskusi Ilmiah Arkeologi, Yogyakarta, 1985 (setensilan hlm. 1-58).

Stein Callenfels, P.V.van. 1926 Epigraphia Balica I, VBG (Verhandelingen van het Kon Bat Gen van Kunsten en Wetenschappen, deel LXVI, G. Kolff \& Co, 1926) 